\title{
REVIEW
}

\section{The effectiveness of current approaches to workplace stress management in the nursing profession: an evidence based literature review}

\section{Mimura, P Griffiths}

Occup Environ Med 2003;60:10-15

The effectiveness of current approaches to workplace stress management for nurses was assessed through a systematic review. Seven randomised controlled trials and three prospective cohort studies assessing the effectiveness of a stress management programmes were identified and reviewed. The quality of research identified was weak. There is more evidence for the effectiveness of programmes based on providing personal support than environmental management to reduce stressors. However, since the number and quality of studies is low, the question as to which, if any, approach is more effective cannot be answered definitively. Further research is required before clear recommendations for the use of particular interventions for nursing work related stress can be made.

See end of article for authors' affiliations

Dr P Griffiths, Primary and Intermedicate Care Section, Florence Nightingale School of Nursing and Midwifery, King's College London, Waterloo Road, London SE 1 8WA, UK: peter.griffiths@kcl.ac.uk

Accepted 19 June 2002
$\mathrm{T}$ he issue of work related stress and stress management in nursing has been widely discussed. The problem can be sufficiently serious that it puts patients at risk $^{1}$ and is implicated in the development of the extreme condition of "burn out". ${ }^{2}$ Stress management techniques proposed have varied across a wide spectrum of approaches, ranging from managing the work environment to reducing external sources of stress to managing the individuals' intrapersonal factors. ${ }^{3}$ To date no systematic review has addressed the question of which, if any, of the approaches to stress reduction described in the literature are most suited for use in the nursing profession. This review attempts to contribute to the development of appropriate approaches to nursing stress management by evaluating current strategies in a systematic manner.

Although there are several models of stress, the bipartite division between the external stressor and the distress response of the individual is common to all. ${ }^{4}$ Stress management techniques can thus be divided into two sorts: environmental management, ${ }^{5}$ which attempts to arrange work environments to reduce the sources of stress; and those approaches that aim to support personnel to deal effectively with a variety of stressful situations. ${ }^{6}$ In this review, therefore, the following question is addressed: which approach, environmental or personnel, is more effective for reducing workplace stress in the nursing profession?

\section{METHODS}

A systematic review was conducted. The following inclusion criteria were used.

- The subjects are nurses.

- Two stress management interventions are compared to each other, or a stress management intervention is compared to a placebo or no intervention control in a prospective way.

- The stress management intervention is clearly described.

- The outcome is change in individual levels of stress and/or of symptoms or sequelae of stress measured by an instrument with evidence of validity.

There was no other restriction in terms of types of participants or settings. Items were limited to 1990 onwards to ensure currency and confined to English and Japanese language for pragmatic reasons.

A facet analysis ${ }^{7}$ was performed to decide terms to be used in an electronic literature search. Several terms were chosen for each facet, namely, "stress", "burnout", "strain", and "distress" for outcome facet. The terms "stress" and "burnout" were searched as index terms where available on a given database. The key words "work", "job", "occupation", "employ", "organisation", and "company" were combined (boolean AND) with a truncated keyword for nurse/nursing. Searches were performed on the Cochrane Library, CINAHL, Medline, PsycINFO, British Nursing Index (BNI) including Royal College of Nursing (RCN) Journals Database, Applied Social Science Index (ASSIA), and Social Science Citation Index (SSCI). Methodological filters were used on CINAHL $^{8}$ and Medline ${ }^{9}$ to restrict results to controlled trials and cohort studies. Adaptations of these filters were applied to other databases.

Reference lists of the retained articles were scanned to find further studies that related to this review. A bibliography concerning psychological stress in the workplace ${ }^{10}$ was also scanned. Two experts in the area of nursing stress were contacted and asked to provide references for searching additional relevant reports.

\section{Analysis and appraisal}

Each study was labelled for the stress management approach according to the above definition,

Abbreviations: $M D$, mean difference; PCS, prospective cohort study; RCT, randomised controlled trial 
Table 1 Findings and appraisals of studies using stress scale

\begin{tabular}{|c|c|c|c|c|c|c|c|}
\hline & Taylor (1991), USA & Kwandt (1992), USA & $\begin{array}{l}\text { Razavi et al (1993), } \\
\text { Belgium }\end{array}$ & $\begin{array}{l}\text { Tsai and Crockett (1993), } \\
\text { Taiwan }\end{array}$ & Carson et al (1999), UK & $\begin{array}{l}\text { Lee and Crockett (1994), } \\
\text { Taiwan }\end{array}$ & Proctor et al (1998), UK \\
\hline \multicolumn{8}{|l|}{ Design features } \\
\hline Type of study & RCT & RCT & RCT & RCT & RCT & RCT & PCS \\
\hline \multirow[t]{2}{*}{ Population } & $\begin{array}{l}102 \text { nurses } \\
\text { Ta35, Tb34, C33 }\end{array}$ & $\begin{array}{l}31 \text { psychiatric nurses } \\
\text { Ta11, Tb10, P10 }\end{array}$ & $\begin{array}{l}72 \text { nurses } \\
\text { T36, C36 }\end{array}$ & $\begin{array}{l}134 \text { nurses } \\
T \text { ? } P \text { ? }\end{array}$ & $\begin{array}{l}53 \text { mental health nurses } \\
\text { T27, P26 }\end{array}$ & $\begin{array}{l}57 \text { nurses } \\
\text { T29, P28 }\end{array}$ & $\begin{array}{l}84 \text { care assistants } \\
\text { T42, C42 }\end{array}$ \\
\hline & & & & & & & \\
\hline Focus of intervention & $\begin{array}{l}\text { Ta: exercise } \\
\text { Tb: music (P) }\end{array}$ & $\begin{array}{l}\text { Ta: humour } \\
\text { Tb: relaxation (P) }\end{array}$ & Education + role-playing (P) & Education + relaxation (P) & Social support education (P) & Cognitive techniques (P) & Education + training $(\mathrm{E})$ \\
\hline Duration & 6 week $(360 \mathrm{~h})$ & 1 session $(3 \mathrm{~h})$ & 8 weeks $(24 h)$ & 5 weeks (13.5h) & 5 weeks (10h) & 2 weeks (12h) & 6 months regularly \\
\hline $\begin{array}{l}\text { Reliability and validity of } \\
\text { scale }\end{array}$ & Previous R\&V data reported & Previous R\&V mentioned & $\begin{array}{l}\text { Previous R stated } \\
\text { Modified by authors }\end{array}$ & Previous $V$ data reported & Previous R\&V mentioned & Present $R$ data reported & $R \& V$ not mentioned \\
\hline Authors' conclusion & Effective & $\begin{array}{l}\text { Not successful but can } \\
\text { reduce stress }\end{array}$ & Effective & Effective & No significant advantage & Effective & $\begin{array}{l}\text { Not clear (further research } \\
\text { needed) }\end{array}$ \\
\hline \multicolumn{8}{|l|}{ Validity of results } \\
\hline Randomisation & Strategy not clear & Strategy not clear & - & Questionable & - & Not reported & N/A \\
\hline Sample attrition & $\begin{array}{l}\text { 9, characteristics } \\
\text { considered }\end{array}$ & $\begin{array}{l}11 \text {, not considered in } \\
\text { analysis }\end{array}$ & $\begin{array}{l}4 \text {, not considered in } \\
\text { analysis }\end{array}$ & $\begin{array}{l}3 \text {, not considered in } \\
\text { analysis }\end{array}$ & $\begin{array}{l}11 \text {, not considered in } \\
\text { analysis }\end{array}$ & $\begin{array}{l}3 \text {, not considered in } \\
\text { analysis }\end{array}$ & $\begin{array}{l}14, \text { not considered in } \\
\text { analysis }\end{array}$ \\
\hline Blinding & Not given & Researcher blind & Not given & Not given & Not given & - & Not given \\
\hline Similarity at start & Not considered & Stress levels not reported & Stress levels not reported & Not clear & - & - & - \\
\hline Confounding factors & $\begin{array}{l}\text { Characteristics of control } \\
\text { not considered }\end{array}$ & $\begin{array}{l}\text { Equal treatment and effects } \\
\text { of placebo not considered }\end{array}$ & $\begin{array}{l}\text { Equal treatment aside from } \\
\text { intervention not reported }\end{array}$ & $\begin{array}{l}\text { Effects of placebo on stress } \\
\text { not considered }\end{array}$ & $\begin{array}{l}\text { Effects of placebo on stress } \\
\text { not considered }\end{array}$ & $\begin{array}{l}\text { Placebo intervention might } \\
\text { worsen stress }\end{array}$ & $\begin{array}{l}\text { Managerial climate change } \\
\text { during the study }\end{array}$ \\
\hline \multicolumn{8}{|l|}{ Authenticity of differences } \\
\hline Main outcome (scale) & $\begin{array}{l}\mathrm{Ta}=-4.1 \quad \mathrm{~Tb}=-1.5 \\
\mathrm{C}=+1.2\end{array}$ & $\begin{array}{l}T a=128.9 \mathrm{~Tb}=137.9 \\
\mathrm{C}=125.6\end{array}$ & Not reported & $\mathrm{T}=-0.7 \mathrm{C}=-0.2$ & $\mathrm{~T}=-3.0 \mathrm{P}=-11.5$ & $T=-8.1 P=-2.0$ & Larger increase in $C$ than $T$ \\
\hline \multirow[t]{2}{*}{ Statistical test } & Post hoc $\chi^{2}$ & ANCOVA & Fisher & ANCOVA & Wald test & ANOVA & Mann-Whitney \\
\hline & $\begin{array}{l}\text { Ta-Tb: not significant } \\
\text { Ta-C Tb-C: significant }\end{array}$ & Not significant & Not significant & Significant & Significant & Significant & $\begin{array}{l}\text { Not significant on all } \\
\text { subscales }\end{array}$ \\
\hline Way of comparison & - & $\bullet$ & Within group analysis & $\begin{array}{l}\text { Measurement timing not } \\
\text { proper }\end{array}$ & $\bullet$ & $\bullet$ & Total score not analysed \\
\hline Clinical significance & Not clear & Described but not discussed & Not reported & Not clear & Not clear & Not clear & Not clear \\
\hline Conclusion of appraisals & Potentially effective & Evaluation impossible & Evaluation impossible & Potentially effective & $\begin{array}{l}\text { Questioned but possibly } \\
\text { effective }\end{array}$ & Effective but questionable & $\begin{array}{l}\text { No evidence of } \\
\text { effectiveness but possibly } \\
\text { effective }\end{array}$ \\
\hline
\end{tabular}


Table 2 Findings and appraisals of studies using stress related scale

\begin{tabular}{|c|c|c|c|}
\hline & Russler (1991), USA & $\begin{array}{l}\text { Berg et al (1994), Hallberg and } \\
\text { Norberg (1993), Sweden }\end{array}$ & Melchior et al (1996), Netherlands \\
\hline \multicolumn{4}{|l|}{ Design features } \\
\hline Type of study & RCT & PCS & PCS \\
\hline \multirow[t]{2}{*}{ Population } & 57 student nurses & 2 wards (31 nurses) & 161 nurses \\
\hline & $\mathrm{T} 19, \mathrm{P} 19, \mathrm{C} 19$ & $\mathrm{~T} 16, \mathrm{C} 15$ & $\mathrm{~T} 60, \mathrm{C} 101$ \\
\hline Focus of intervention & $\begin{array}{l}\text { Cognitive education + role playing } \\
\text { (P) }\end{array}$ & $\begin{array}{l}\text { Nursing method change + } \\
\text { supervision }(E)\end{array}$ & $\begin{array}{l}\text { Nursing method change + support } \\
\text { training }(E)\end{array}$ \\
\hline Duration & 1 semester $(16 \mathrm{~h})$ & 1 year constantly & 1 year constantly \\
\hline Reliability and validity of scale & Present $R$ data reported & 3 scales, present R\&V data reported & Previous R\&V mentioned \\
\hline Authors' conclusion & $\begin{array}{l}\text { Effective when analysed as overall } \\
\text { subjects }\end{array}$ & Reduce negative effects & $\begin{array}{l}\text { Potentially effective (decreased } \\
\text { turnover and stable stress) }\end{array}$ \\
\hline \multicolumn{4}{|l|}{ Validity of results } \\
\hline Randomisation & Strategy not clear & N/A & $\mathrm{N} / \mathrm{A}$ \\
\hline Sample attrition & Not clear & 8, not included in analysis & Not reported \\
\hline Blinding & Not given & Not given & Not given \\
\hline Similarity at start & $\cdot$ & $\bullet$ & $\bullet$ \\
\hline Confounding factors & $\begin{array}{l}\text { Effects of placebo on stress not } \\
\text { considered }\end{array}$ & Not reported & Imitation of intervention by $\mathrm{C}$ \\
\hline \multicolumn{4}{|l|}{ Authenticity of differences } \\
\hline Main outcome (scale) & Not reported & Larger decrease in $T$ than $C$ & Stable in both $T$ and $C$ \\
\hline \multirow[t]{2}{*}{ Statistical test } & ANOVA & Mann-Whitney & ANCOVA \\
\hline & Not significant on all subscales & Not significant on most subscales & Not consistent \\
\hline Way of comparison & Overall analysis & $\begin{array}{l}\text { Total score not analysed } \\
\text { Within group analysis }\end{array}$ & Total score not analysed \\
\hline Clinical significance & Not reported & Not clear & Not clear \\
\hline Conclusion of appraisals & Evaluation impossible & Potentially effective & Evaluation impossible \\
\hline
\end{tabular}

and reviewed individually. Data synthesis was not attempted since the studies included used a diversity of interventions and measurement instruments. All the studies were appraised in accordance with the Critical Appraisal Skills Programme checklist $^{11}$ and the guidelines by Oxman and Guyatt. ${ }^{12}$

\section{RESULTS}

\section{Overall features and findings}

It was found during the development of the search strategy that a large number of survey or retrospective studies have examined stress in the nursing profession, whereas randomised controlled trials (RCTs) and prospective cohort studies (PCSs) are rare. Eleven studies meeting the inclusion criteria were identified and all were retrieved.

The randomisation strategy in two works ${ }^{13}{ }^{14}$ appeared quite doubtful, so these studies were treated as PCSs. It was found that four papers ${ }^{14-17}$ only measured the symptoms or sequelae of stress; thus these studies are treated separately. Of these four, two articles ${ }^{16}{ }^{17}$ were treated as one study since they reported research using the same sample and intervention but different measurement. This review thus involved six RCTs, one PCS (table 1), and three auxiliary studies (table 2). All were published in the English language.

Of six RCTs, two were conducted in the USA, ${ }^{18}{ }^{19}$ two in Taiwan, ${ }^{2021}$ and two in other Western countries. ${ }^{22}{ }^{23}$ Four studies investigated registered general nurses, ${ }^{18}{ }^{20-22}$ and two psychiatric or mental health nurses. ${ }^{19}{ }^{23}$ Interventions involved various methods: education, ${ }^{20}{ }^{22} 23$ role playing, ${ }^{22}$ relaxation, ${ }^{19}{ }^{20}$ music, ${ }^{18}$ exercise, ${ }^{18}$ humour, ${ }^{19}$ and cognitive techniques. ${ }^{21}$ Interventions generally lasted for several weeks. Additionally one $\mathrm{PCS}^{13}$ evaluated an intervention of education and training in Europe, which used a sample of assistant nurses and examined an environmental approach. The duration of this study was six months.

Three auxiliary studies included one $\mathrm{RCT}^{15}$ and two PCSs $^{14}{ }^{16}{ }^{17}$ in Western countries. Two were conducted on registered general nurses ${ }^{14}{ }^{16}{ }^{17}$ and the other on student nurses. ${ }^{15}$ One examined cognitive education plus role playing ${ }^{15}$ and two investigated changing nursing method. ${ }^{14} 16$ 17 All studies lasted for a relatively long duration, from six months to one year.

\section{Critical appraisals}

No quality criteria additional to the guidelines ${ }^{11} 12$ were imposed, but relevant dimensions of quality were extracted and are reported below. The database on which each study was identified is also reported following the author(s), published year, and country where the study was conducted. Tables 1 and 2 present a synopsis of design features and appraisals.

\section{Personnel support interventions}

Taylor (1991), USA, ${ }^{18}$ Cochrane Library

An exercise and a music programme was examined using two treatment groups and a no intervention control which was waiting for the active intervention to be available. Assignment to groups was random. Sample attrition was low and considered in the analysis. Both treatment interventions are categorised as personnel support. Stress levels were measured by the Perceived Stress Scale. ${ }^{24}$ Reduced stress was observed in the exercise group (mean difference $(\mathrm{MD})=-4.1$ ) and the music group $(\mathrm{MD}=-1.5)$ after the intervention, but stress increased in the control group $(\mathrm{MD}=+1.2)$ (possible scores $=0-56)$. The difference in stress reduction between the two treatments was not significant, although the difference against the control was significant for both treatments. However, the clinical significance of the stress reduction was unknown. Furthermore, the effects of the control condition were not clear: whether or not only waiting for the programmes to be provided could increase stress level. It should be concluded that the exercise and music programmes are potentially effective, but this should be viewed with caution.

Kwandt (1992), USA, ${ }^{19}$ CINAHL

The effect of a humour and a relaxation programme was tested. Both programmes are classified as personnel support. A placebo group received a workshop on the use of neurological assessment. The interventions were provided in only one session, which lasted for three hours. Allocation to groups was random. According to the Psychiatric Nurses' Occupational Stress Scale, ${ }^{25}$ the mean post-test score adjusted for pretest level was highest in the relaxation group (137.9), next in the humour group (128.9), and lowest in the control group 
(125.6) (possible scores $=0-158$ ). The differences were not significant. The same results were shown generally in the subscales. Methodological weakness is noted due to the small sample size and large attrition. Therefore, it is impossible to draw conclusions.

\section{Razavi et al (1993), Belgium, ${ }^{22}$ Cochrane Library}

This study investigated an educational programme which is classified as personnel support. A control group received no intervention. Allocation to groups was random. A translated and modified version of the Nursing Stress Scale ${ }^{26}$ was used to measure stress levels. No score on the scale was reported, only the statistical significance of the differences. Although the authors concluded that the programme was effective, this is difficult to support owing to a number of weaknesses in the study design. The largest one is the lack of between group comparison, which makes the randomised controlled design largely meaningless. Changes in stress level were reported at different times between the two groups. Reliability and validity of the scale modified by the author was not tested. Thus, it would be impossible to estimate the effectiveness of the programme on the basis of this report.

Tsai and Crockett (1993), Taiwan, ${ }^{20}$ Cochrane Library

A relaxation training programme was examined. The programme is considered to focus on personnel support. A placebo intervention consisted of an equal number of lectures on theory analysis. Allocation to groups was random. The programme used a Chinese version of the Nurse Stress Checklist $^{27}$ in nine point Likert format. The results showed a larger decrease in stress in the treatment group $(\mathrm{MD}=-0.7)$ than the placebo group ( $\mathrm{MD}=-0.2$ ), which was statistically significant. The researchers also used another scale of stress related phenomenon, the Chinese General Health Questionnaire ${ }^{28}$; scores on this indicated alike results. The major weakness is that the conclusion was made without taking the influence of placebo intervention on stress into consideration. Equally the timing of administering the scales was not ideal, with assessments being conducted at the end of the first session and at the beginning of the last session. Although the treatment group showed a greater decrease in stress than the placebo group, the findings should be viewed with caution due to potential bias.

\section{Carson et al (1999), UK, ${ }^{23} \mathrm{CINAHL}$}

This study compared an educational programme and a placebo intervention. The treatment intervention is regarded as personnel support. The placebo group was provided with a booklet on stress management and feedback on the scores on the same questionnaires as the treatment. Allocation to groups was random. The trial used the DeVilliers Carson Leary Stress Scale ${ }^{29}$; results indicated greater stress reduction in the placebo group $(\mathrm{MD}=-11.5)$ than the treatment group $(\mathrm{MD}=$ -3.0). These differences were statistically significant. Although the placebo group did show better results than the treatment group, the level of stress decreased after the intervention in the treatment group as well. Scores on two other scales which dealt with stress related concepts, the General Health Questionnaire ${ }^{30}$ and the Maslach Burnout Inventory, ${ }^{31}$ also supported this result. The effect of the intervention is questioned, yet possibly effective. A large attrition of subjects within the small sample size could affect the results. Also, the effects of the placebo intervention were unknown.

\section{Lee and Crockett (1994), Taiwan, ${ }^{21}$ Cochrane Library}

The authors examined a programme of assertiveness training, which is regarded as personnel support. A placebo intervention consisted of sessions about new technology on computer applications. This study was only one within this review which accomplished blinding the subject to whether the intervention they received was treatment or placebo. Allocation to groups was random. A Chinese version of the Perceived Stress Scale ${ }^{24}$ was used, reporting empirical data for validity. Results showed a greater decrease in stress among the treatment group $(\mathrm{MD}=$ $-8.1)$ than the placebo group $(\mathrm{MD}=-2.0)$. The difference was statistically significant. However, the placebo intervention could be suspected to burden the recipients and produce feelings of stress. It is therefore concluded that the programme may be effective, but should be viewed with caution.

\section{Russler (1991), USA, ${ }^{15}$ Medline}

This study investigated a cognitive, behavioural, and physiological programme. The intervention is labelled as personnel support. It was compared to a placebo, self awareness programme involving self writing and identification of stressors, and a no intervention control. Allocation to groups was random. The State-Trait Anxiety Inventory ${ }^{32}$ was used with no direct assessment of stress. Statistical tests of the results indicated no significant difference between the three groups on any subscales at pre- or post-treatment. Because of failing to report stress level scores, it is not possible to review the changes in stress level. Furthermore, effects of the placebo intervention were not considered in the analysis. Therefore, it would be impossible to conclude whether the programme is effective or not.

\section{Environmental management interventions Proctor et al (1998), UK, ${ }^{13}$ Cochrane Library}

This study examined the effect of providing structured training and a regular support programme. Although the intervention was described as an educational schedule in the report, it is regarded in effect as introducing a changed nursing method. The intervention is therefore considered as environmental management rather than personnel support. A control group received no intervention. Method of allocation to groups was in effect not random. The Occupational Stress Indicator ${ }^{33}$ was used. Stress was increased on all subscales post-intervention in both the treatment and control groups (total scores were not reported). The differences between groups were not significant. Scores on the General Health Questionnaire ${ }^{34}$ supported this finding.

When reviewed as a PCS, this is a relatively well conducted investigation. Sample size was reasonably large and the treatment and control groups were similar in nature and number. The intervention was administered for a relatively long term. Methodological weakness involves the large sample attrition not included in the analysis and the lack of analysis using total scores. There were organisational and managerial changes in some institutions under the study, which possibly influenced the increase in stress level in both treatment and control groups. However, if comparing the changes in stress level carefully, the degree of increase was greater in the control group than the treatment group on all indicators. It could be said that the programme is not successful as the differences between the two groups were not statistically significant, yet it is possibly effective for reducing stress level.

Berg et al (1994), and Hallberg and Norberg (1993),

Sweden, ${ }^{16}{ }^{17}$ Cochrane Library and hand search

The effect of introducing individualised nursing care was tested. The methods are regarded as environmental management. Nurses on an intervention ward were compared to those on a control ward. Stress related psychological dimensions were quantified by three validated scales, the Swedish version of the Burnout Measure, ${ }^{35}$ the Maslach Burnout Inventory, ${ }^{36}$ and the Strain in Nursing Care Scale developed by the researchers. Change in stress level after the intervention showed a larger decrease in the treatment group on all subscales; however, all statistical tests indicated this to be non-significant. This investigation was carefully conducted, with well thought selection of the wards and standardisation 
of the participants' views and knowledge at the start. The results of statistically not significant differences were possibly because of the small sample size in each group and large attrition relative to it. Failing to analyse with total scores also makes it difficult to accurately estimate the effectiveness of the programme since the validity of the scales was based on their total scores. Thus the positive effect should be viewed with caution.

\section{Melchior et al (1996), Netherlands, ${ }^{14}$ Cochrane Library}

The effect of introducing primary nursing in hospital wards was examined. The intervention represents changing the work environment, and is thus environmental management. No intervention was given on control wards. The stress related measurement used was a translated version of the Maslach Burnout Inventory. ${ }^{37}$ Analysis of the results showed stable stress level at pre- and post-treatment in both treatment and control groups. Analysis was done with subscales only, and results of total score were not provided. It was reported that there was imitation of the intervention by the control group due to an information leakage. It is therefore impossible to draw conclusions.

\section{Summary of results}

Among the response support interventions, one approach focusing on cognitive techniques was determined to be effective, although evidence was weak; three approaches on exercise, music, and relaxation training were potentially effective; one approach of social support education is questioned but possibly effective; and two are impossible to draw conclusions after the critical appraisals. One auxiliary study on cognitive education and role playing allowed no conclusion. One study focusing on environmental change (introducing different nursing method) provided no evidence of effectiveness (non-significant results), although findings tended to favour the intervention and so the study is classified as possibly effective. With regard to the auxiliary studies, one approach of changing nursing method (environmental change) is potentially effective and one further study allows no conclusion to be drawn.

In line with the bipartite categorisation described above, it seems that there is more evidence for the effectiveness of personal support than environmental management for reducing workplace stress in the nursing profession. However, it is not possible at this stage to determine what kind of approach is more effective, because the number of studies is too small to compare different approaches.

\section{DISCUSSION \\ Methodological weakness of identified studies}

Sample size was on the whole small with no power analysis presented. In most reports, it is ambiguous whether statistical non-significance was due to type II error or a real phenomenon. Also, sample attrition was often high and rarely considered in analysis.

Selecting an appropriate placebo is a major issue for research in this area in particular. Feeling stress is a quite subjective phenomenon and it cannot be assumed that a placebo is neutral. Listening to music or receiving supportive sessions may reasonably have either positive or negative impacts on stress as interventions in themselves. A placebo intervention, therefore, must be chosen with careful consideration, and ideally the influences of the placebo intervention on stress should be already clear. Five investigations in this review used a placebo intervention, yet they did not clarify its influences on stress level. In one study ${ }^{23}$ the placebo intervention appeared to be an active and effective stress reducing intervention. This is a serious problem in disentangling placebo effect, hawthorn effect, maturation, etc, and it remains unclear whether the results of some studies here were due to genuine effects of the treatment intervention or not.

Many studies used within group and subscale analysis to draw conclusions. Such analyses may be useful for exploratory examination, but are not superior to between group and total score analysis. The statistical procedures used seem appropriate in all studies and those results were presented in detail, but actual differences in stress levels were not exhibited in some reports. More importantly, no article discussed clinical significance of the changes in stress level, simply concentrating on statistical significance. It may be difficult to judge the clinical significance of changes on a stress scale, but some index such as normative scores should be referred to, or the issue should be mentioned.

Few programmes studied here were based on a clearly defined model of stress. Consequently, current stress management programmes seem to be a sort of guesswork. It is certain that the various theories of stress offer frameworks that can be used to categorise components and goals of intervention and that categorisation and description of interventions should not be regarded as non-problematic. Conceptual clarity in future research would help to identify which aspects of the stress mechanism the programme is designed to affect.

\section{Implications for practice and future research}

It is not possible to recommend any particular approach for practical implementation because the number of studies is too small to determine it. However, there is more evidence for the effectiveness of personnel support than environmental management. Moreover all programmes reviewed here appeared at least not harmful. Further research is definitely needed, specifically RCTs or PCSs with rigour. This review strongly suggests the need for experimental research on stress management programmes which overcome the limitations pointed out in the critical appraisals and methodological weakness.

Nursing research has emphasised the utility of a multidimensional format for stress management, accounting for the multidimensional nature of the stress response. ${ }^{38}$ The multifaceted nature of stress makes it unlikely that a single approach would provide optimal stress management in the workplace. However, the effects of beneficial components might be diluted by useless components when a multicomponent programme is tested. ${ }^{15}$ Although complex interactions in multifaceted interventions may be a necessary component, unless the interaction is clarified it would seem that small scale research is more likely to contribute to knowledge if it examines single component interventions or programmes where the interaction of components is clearly planned and described.

\section{Authors' affiliations}

C Mimura, P Griffiths, Florence Nightingale School of Nursing and Midwifery, King's College London, UK

\section{REFERENCES}

1 Fresco A, Norfolk A. Patients put at risk as stress rises in nursing. The Times. London: Friday, 12 May 2000:5L.

2 Schaufeli W. Burnout. In: Firth-Cozens J, Payne RL, eds. Stress in health professionals: psychological and organisational causes and interventions. Chichester: John Wiley \& Sons, 1999: 17-32.

3 Firth-Cozens J, Payne RL, eds. Stress in health professionals: psychological and organisational causes and interventions. Chichester John Wiley \& Sons, 1999

4 Payne RL. Stress at work: a conceptual framework.In: Firth-Cozens Payne RL, eds. Stress in health professionals: psychological and organisational causes and interventions. Chichester: John Wiley \& Sons, 1999:3-16.

5 Murphy LR. Organisational interventions to reduce stress in health care professionals. In: Firth-Cozens J, Payne RL, eds. Stress in health professionals: psychological and organisational causes and interventions. Chichester: John Wiley \& Sons, 1999: 149-162. 
6 Hardy GE, Barkham M. Psychotherapeutic interventions for work stress. In: Firth-Cozens J, Payne RL, eds. Stress in health professionals: psychological and organisational causes and interventions. Chichester: John Wiley \& Sons, 1999:247-59.

7 Sackett D, Richardson W, Rosenberg W, et al. Evidence based medicine: how to practice and teach EBM. New York: Churchill Livingstone, 1997.

8 Miner Library, University of Rochester. Search strategy for Cinahl (OVID). http://www.urmc.rochestetr.edu/Miner/Educ/ebnfilt.htm, September 2000

9 Greenhalgh T. How to read a paper. London: BM Publishing, 1997.

10 Grimshaw J. Employment and health: psychological stress in the workplace. London: The British Library, 1999.

11 Spittlehouse C, Institute of Health Science. CASP 11 questions to help you make sense of a trial. http://www.his.ox.ac.uk/casp/rct.html, September 2000

12 Oxman AD, Guyatt GH. A consumer's guide to subgroup analyses. Ann Intern Med 1992;116:78-84

13 Proctor R, Stratton-Powell H, Tarrier N, et al. The impact of training and support on stress among care staff in nursing and residential homes for the elderly. J Ment Health 1998;7:59-70.

14 Melchior ME, Philipsen H, Abu-Saad HH, et al. The effectiveness of primary nursing on burnout among psychiatric nurses in long-stay settings. J Adv Nurs 1996;24:694-702.

15 Russler MF. Multidimensional stress management in nursing education. J Nurs Educ 1991;30:341-6.

16 Berg A, Hansson UW, Hallberg IR. Nurses' creativity, tedium and burnout during 1 year of clinical supervision and implementation of individually planned nursing care: comparisons between a ward for severely demented patients and a similar control ward. J Adv Nurs 1994;20:742-9.

17 Hallberg IR, Norberg A. Strain among nurses and their emotional reactions during 1 year of systematic clinical supervision combined with the implementation of individualized care in dementia nursing. J Adv Nurs 1993:18:1860-75.

18 Taylor MW. Effects of initial stress level, social support, and participation in an exercise or music condition on the posttreatment stress, depression, and anxiety of nurses. ED.D., St John's University, 1991.

19 Kwandt J. The use of humor to relieve stress in psychiatric nurses. ED.D. The College of William and Mary, 1992.

20 Tsai SL, Crockett MS. Effects of relaxation training, combining imagery, and meditation on the stress level of Chinese nurses working in modern hospitals in Taiwan. Issues in Mental Health Nursing 1993;14:51-66.
21 Lee S Crockett MS. Effect of assertiveness training on levels of stress and assertiveness experienced by nurses in Taiwan, Republic of China. Issues in Mental Health Nursing 1994;15:419-32.

22 Razavi D, Delvaux N, Marchal S, et al. The effects of a 24 -h psychological training program on attitudes, communication skills and occupational stress in oncology: a randomised study. Eur J Cancer 1993;29A: 1858-63.

23 Carson J, Cavagin J, Bunclark J, et al. Focus. Effective communication in mental health nurses: did social support save the psychiatric nurse? NT Research 1999:4:31-42.

24 Cohen S, Kamarck T, Mermelstein R. A global measure of perceived stress. J Health Soc Behav 1983;24:385-96.

25 Dawkins JE, Depp FC, Selzer NE. Stress \& the psychiatric nurse. Journal of Psychosocial Nursing \& Mental Health Services 1985;23:8-15.

26 Gray-Toft P, Anderson J. The Nursing Stress Scale: development of an instrument. J Behav Assess 1981;3:1 1-23.

27 Benoliel JQ, McCorkle R, Georgiadou F, et al. Measurement of stress in clinical nursing. Cancer Nursing 1990;13:221-8.

28 Cheng TA, Wu JT, Chong MY, et al. Internal consistency and factor structure of the Chinese Health Questionnaire. Acta Psychiatr Scand 1990;82:304-8.

29 Fagin L, Carson J, Leary J, et al. Stress, coping and burnout in menta health nurses: findings from three research studies. Int J Soc Psychiatry 1996;42:102-11

30 Goldberg D, Williams P. A user's guide to the General Health Questionnaire. Windsor: NFER-Nelson, 1988.

31 Maslach C, Jackson S. Maslach Burnout Inventory manual. California: Consulting Psychologists Press, 1986

32 Spielberger C, Gorshuch R, Lushene R. The State-Trait Anxiety Inventory: test manual for Form Y. California: Consulting Psychologist Press, 1983.

33 Cooper CL, Sloane SJ, Williams S. Occupational Stress Indicator Data Supplement. Windsor: NFER-Nelson, 1988.

34 Goldberg DP, Hillier VF. A scaled version of the General Health Questionnaire. Psychol Med 1979:9:139-45.

35 Pines A, Aronson E. Career burnout. New York: The Free Press, 1988.

36 Maslach C, Jackson S. The measurement of experienced burnout. J Occup Behav 1981;2:99-113.

37 Schaufeli WB, van Dierendonck D. The construct validity of two burnout measures. Journal of Organizational Behavior 1993;14:631-47.

38 Stoyva J, Anderson C. A coping-rest model of relaxation and stress management. In: Goldberger L, Brenznitz S, eds. Handbook of stress: theoretical and clinical aspects. New York: The Free Press, 1982. 